\title{
Quintais agroflorestais: características agrossociais sob a ótica da agricultura familiar
}

O presente trabalho tem por objetivo investigar aspectos relacionados a características agrossociais sob a ótica dos agricultores familiares residentes em quintais agroflorestais do núcleo rural de Ponte Alta, Gama - Distrito Federal, Brasil. A presente pesquisa se caracteriza metodologicamente como de natureza quantitativa, exploratória e descritiva. A coleta de dados foi realizada por meio da aplicação de questionário estruturado, contendo questões que remetiam à percepção e comportamento do produtor entrevistado sobre a temática em análise. O tratamento dos dados foi realizado por meio de análise estatística descritiva, com o uso do software $R^{2}$. Através da aplicação do questionário foi possivel caracterizar os agricultores familiares residentes em quintais agroflorestais na região estudada. A amostra representou $55,62 \%$ do universo do estudo. Foram entrevistadas 99 pessoas com idade entre 18 e 83 anos. Quando indagados sobre o número de filhos de cada entrevistado, observou-se que $52 \%$ dos entrevistados possui um, dois, três enquanto $10,20 \%$ não possui nenhum filho. A partir desses resultados concluise que os agricultores familiares da região de Ponte Alta - Gama possuem pouco grau de instrução. A fonte de renda que foi considerada mais importante para os entrevistados foi a 'Por fora da propriedade', em que 51,02\% dos indivíduos consideram a principal. Ao observar que a renda obtida a partir de investimentos na propriedade é baixa, verifica-se que os recursos provenientes da unidade de produção não são suficientes para suprir as necessidades das famílias, levando-as a envidar esforços na busca de outras rendas fora da propriedade rural.

Palavras-chave: Desenvolvimento Rural; Extensão Rural; Informação; Sistema Agroflorestal.

\section{Homegardens: agrosocial characteristics from the perspective of family farming}

\begin{abstract}
The present work has the objective of investigating aspects related to agrossocial characteristics from the perspective of family farmers living in agroforestry farms in the rural center of Ponte Alta, Gama - Distrito Federal, Brazil. The present research is characterized methodologically as a quantitative, exploratory and descriptive nature. Data collection was performed through the application of a structured questionnaire, containing questions that referred to the perception and behavior of the interviewed producer on the subject under analysis. The data treatment was performed through descriptive statistical analysis, using the $\mathrm{R}^{2}$ software. Through the application of the questionnaire it was possible to characterize the family farmers residing in agroforestry yards in the studied region. The sample represented $55.62 \%$ of the universe of the study. We interviewed 99 people aged between 18 and 83 years. When asked about the number of children of each interviewee, it was observed that $52 \%$ of respondents had one, two, three while $10.20 \%$ did not have any children. From these results it can be concluded that the family farmers in the Ponte Alta-Gama region have little education. The source of income that was considered most important to the interviewees was the "Out of the rural property", in which $51.02 \%$ of individuals considered the main. Noting that the income obtained from investments in the property is low, it is verified that the resources coming from the production unit are not enough to supply the needs of the families, causing them to make efforts in the search of other rents outside the property rural.
\end{abstract}

Keywords: Rural Development; Rural Extension; Information; Agroforestry System.

Topic: Extensão e Desenvolvimento Rural

Reviewed anonymously in the process of blind peer.

Kever Bruno Paradelo Gomes (iD)

Instituto Federal de Educação, Ciência e Tecnologia de Brasília, Brasil http://lattes.cnpq.br/9188020334213105

http://orcid.org/0000-0001-9398-3277

keverbruno@hotmail.com

Rosana de Carvalho Cristo Martins (iv)

Universidade de Brasília, Brasil

http://lattes.cnpq.br/0255187706160134

http://orcid.org/0000-0001-8066-7566

roccristo@gmail.com

Cledinaldo Aparecido Dias (iD

Universidade Federal de Minas Gerais, Brasil

http://lattes.cnpq.br/6384719963302649

http://orcid.org/0000-0002-7707-9664

cledinaldodias@yahoo.com.br

6

DOI: 10.6008/CBPC2179-6858.2018.004.0009
Received: $10 / 04 / 2018$

Approved: 24/05/2018

Juliana Martins de Mesquita Matos (iD

Universidade de Brasília, Brasil

http://lattes.cnpq.br/0453235192511777

http://orcid.org/0000-0001-7766-9659

julianamartins21@gmail.com
Referencing this:

GOMES, K. B. P.; MARTINS, R. C. C.; DIAS, C. A.; MATOS, J. M. M. Quintais agroflorestais: características agrossociais sob a ótica da agricultura familiar. Revista Ibero Americana de Ciências Ambientais, v.9, n.4, p.111-124, 2018. DOI: http://doi.org/10.6008/CBPC21796858.2018.004.0009 


\section{INTRODUÇÃO}

No contexto contemporâneo, o grande impulso do agronegócio brasileiro é amplificar formas de uso da terra que sejam praticáveis economicamente e, ao mesmo tempo, ecologicamente sustentáveis (TÉO et al., 2012). Recentes publicações da 'Food and Agriculture Organization of the United Nations', abordam que a degradação do solo pode ocasionar sérias implicações para os meios de permanência das populações rurais, diminuindo o abastecimento de água de boa qualidade e reduzindo a segurança alimentar e nutricional. Ao longo do tempo, a perda da biodiversidade pode aumentar a vulnerabilidade das comunidades rurais aos riscos ambientais e aos efeitos das mudanças climáticas (FAO, 2017).

Os sistemas agroflorestais ( $S A F^{\prime}$ s) apresentam uma abordagem fértil e auspiciosa para a gestão dos recursos naturais, pois possibilita conectar metas de desenvolvimento agrícola sustentável para os agricultores familiares, em recursos tropicais com maiores benefícios ambientais do que as culturas agrícolas tradicionais em sistemas de monocultura (SCHROTH et al., 2004; AJEESH et al., 2015). Os SAF's estão representados por vários sistemas de exploração agropecuária, como a 'cultivation' (agricultura itinerante), sistema de 'taungya', consórcios agroflorestais comerciais, sistemas agrosilvopastoril, agrosilvicultura, silvipastoril, quintais agroflorestais ou 'homegardens', hortos caseiros, entre outros (PEREIRA et al., 2010; MACEDO, 2009).

De acordo com Brito et al. (2000), quintal é o termo utilizado para se referir ao terreno situado ao redor da propriedade da família, definido, na maioria das vezes, como a porção de terra próxima a casa, de fácil acesso, no qual cultivam ou se mantem múltiplas espécies que fornecem parte da alimentação familiar, bem como outros produtos, como lenha, ornamental e plantas medicinais. Este fato também foi observado por Pereira et al. (2015), sendo uma expressão cultural revelada pelo cultivo e manejo de diversas espécies vegetais.

No Brasil, os pequenos agricultores julgam os sistemas agroflorestais como meios de uso da terra que fornecem recursos socioeconômicos e benefícios ambientais (CASTRO et al., 2017, ROSA et al., 2009). Os SAF's permitem que os agricultores familiares possam obter renda de diferentes espécies e produtos ao longo do ano. Apesar dessas vantagens, há uma ausência de informações com relação ao manejo dos SAF's, à silvicultura das espécies que compõem os mesmos, ao desenho e ao arranjo desses sistemas por parte dos agricultores familiares, os quais, na maioria das vezes têm mais instrução quanto a cultivos agrícolas tradicionais (VIEIRA et al., 2007).

Quando se objetiva analisar o ponto de vista de agricultores familiares é necessário, segundo Lopes et al. (2011), buscar o conhecimento da percepção dos agricultores, uma vez que será possível visualizar as relações que permeiam estas percepções e seus reflexos na subjetividade dos produtores. A descrição do perfil agrossocial permite a apreensão da conjuntura em que se deparam os protagonistas da agricultura familiar e as escolhas possíveis para o seu desenvolvimento.

Assimilar as diversas dimensões sociais, políticas e ambientais e fortalecer ações que busquem o desenvolvimento local de comunidades rurais é crucial para que haja o empoderamento dos agricultores 
familiares, fomentando a autonomia e consciência para escolher o tipo de desenvolvimento que almejam, em busca da soberania econômica e alimentar, equidade social, ao passo que também recuperam o ambiente em desequilíbrio (FRANCO et al., 2017). Ponderados os delineamentos desse cenário, o presente trabalho tem por objetivo investigar aspectos relacionados a características agrossociais soba ótica dos agricultores familiares residentes em quintais agroflorestais do núcleo rural de Ponte Alta, Gama - Distrito Federal, Brasil.

\section{MATERIAIS E MÉTODOS}

Considerando os objetivos propostos a presente pesquisa se caracteriza metodologicamente como de natureza quantitativa, exploratória e descritiva. Como exploratório-descritiva o estudo tem como finalidade o desenvolvimento, esclarecimento e modificação de ideias e conceitos já organizados na literatura; traçando características e comportamentos dos agricultores familiares estudados, relacionando os fenômenos vivenciados por eles e estabelecendo relações a partir da pesquisa de campo e coleta de dados padronizados (GIL, 1999; MATTAR, 1999). Marconi et al. (2004) atentam que esse tipo de pesquisa se apropria de diferentes técnicas de pesquisa e busca reunir o detalhamento do maior número de informações possíveis, na busca de apreender e descrever a complexidade das situações.

O trabalho foi realizado em propriedades rurais dos agricultores familiares do Núcleo Rural Ponte Alta, Região Administrativa do Gama, na cidade de Brasília, Distrito Federal - Brasil. De acordo com dados da Empresa de Assistência Técnica e Extensão Rural do Distrito Federal (EMATER, 2017) a Região rural de Ponte Alta do Gama conta atualmente com um universo de 178 pequenos agricultores familiares.

Para a seleção das propriedades rurais pesquisadas foram considerados os seguintes critérios: Ser agricultor familiar de acordo com a Lei 11.326/2006 - no Distrito Federal quatro módulos fiscais equivalem a 20 hectares (INCRA, 2013) e; realizar atividade agrícola ou pecuária na propriedade. O tamanho da amostra correspondeu a 99 produtores familiares do núcleo rural de Ponte Alta - Gama, calculado com base na equação definida por Trioula (2008). A escolha da amostra obedeceu a um critério não-probabilístico em que nem todos os elementos da população tiveram a mesma probabilidade de serem incluídos na amostra. Nesta, o pesquisador selecionou membros da população de acordo com a acessibilidade e disponibilidade para participação.

A coleta de dados foi realizada por meio da aplicação de questionário estruturado, contendo questões que remetiam à percepção e comportamento do produtor entrevistado sobre a temática em análise. Com o apoio dos informantes, em alguns casos, foi utilizado a técnica 'bola de neve' (BAILEY, 1982). Nesta metodologia uma informante chave da comunidade previamente selecionado, recomenda outro informante, repetindo-se o processo a partir de novos entrevistados. O tratamento dos dados foi realizado por meio de análise estatística descritiva, com o uso do software $R^{2}$ versão 3.4.0 (R CORE TEAM, 2016). Esse software permitiu a execução dos cálculos e gráficos para tabulação e análise das variáveis do banco de dados criado. 


\section{RESULTADOS E DISCUSSÃO}

Através da aplicação do questionário foi possível caracterizar os agricultores familiares residentes em quintais agroflorestais na região estudada. A amostra representou 55,62\% $(99 / 178=55,617)$ do universo do estudo. As características socioeconômicas estão relacionadas segundo Rodriguez-Ocaña (1996) à idade do indivíduo, escolaridade, fontes de renda, existência de custo de produção, bem como participação ou não em cooperativas de produtores rurais.

Foram entrevistadas 99 pessoas com idade entre 18 e 83 anos (Tabela 1), tendo em média 49 anos. A maioria, 58,59\% ( $N$ 58) é homem. Entretanto, no decorre das entrevistas, mesmo o informante sendo do sexo masculino, houve bastante interação das mulheres nos diversos questionamentos, sejam elas esposa, filha ou irmã.

Tabela 1: Tabela de frequência referente ao sexo e de idade dos informantes.

\begin{tabular}{|l|l|l|l|}
\hline Sexo & $58,59 \%$ & Idade* & $4,3 \%$ \\
\hline Masculino & $41,41 \%$ & 11 a 20 & $4,3 \%$ \\
\hline Feminino & & 21 a 30 & $19,35 \%$ \\
\hline & & 31 a 40 & $24,73 \%$ \\
\hline & & 41 a 50 & $26,88 \%$ \\
\hline & & 51 a 60 & $10,75 \%$ \\
\hline & & 61 a 70 & $7,52 \%$ \\
\hline & & 71 a 80 & $2,15 \%$ \\
\hline N & 99 & 80 a 90 & 93 \\
Total & $100 \%$ & N & $100 \%$ \\
\hline
\end{tabular}

*Seis pessoas não responderam à questão idade.

Na faixa etária superior, que contém a população considerada idosa, a tendência demográfica internacional é a de dominância do número de mulheres (IPARDES, 2007). O debate sobre gênero e agricultura familiar tem florescido bastante nos últimos anos segundo Siliprandi (2007), centrado tanto na invisibilidade do trabalho feminino nas atividades produtivas e reprodutivas, como nas perspectivas que se abrem para as mulheres com a ascensão cada vez maior das atividades não agrícolas como geradoras de renda no meio rural.

Para Sales (2007) é evidente a existência das mulheres rurais na produção agrícola familiar. Mesmo na ausência de visibilidade não se pode desconhecer que elas estão manuseando terras, plantando, colhendo, e cultivando o querer de ter uma terra livre e usufruí-la com seu trabalho. Segundo Vasquez et al. (2014) as mulheres residentes no meio rural, além de cuidar da casa e dos filhos, tem ampla participação nas atividades agrícolas da propriedade familiar.

Ao estudar diversos quintais no estado de Goiás, Silva et al. (2016) apontou que $82 \%$ dos informantes era do sexo feminino. Bem próximo a estes dados, cerca de 70,9 \% dos informantes do sexo feminino foram relatados por Santos et al. (2008) em quintais agroflorestais na região de Alta Florestal - MT. Em quintais agroflorestais no estado do Piauí, Pereira et al. (2016) entrevistaram 85 agricultores familiares, sendo 65 mulheres e 20 homens, com faixa etária média de 60 anos de idade.

Uma observação importante que pode interferir no processo de adoção de práticas agroecológicas é o fato da resistência das pessoas (agricultor (a) e demais membros da família) na adoção de inovações. De 
acordo com Maravieski et al. (2008) “Estar em um ambiente de comodidade é mais seguro e mais confortável para os indivíduos. De certa maneira tudo o que foge da comodidade, do conhecido, traz uma tendência natural de resistência". Corroborando, Kotter et al. (2000) pontuam que o desejo de não perder algo de valor; o entendimento equivocado; a crença de que a mudança não faz sentido e a baixa tolerância à mudança apresentam-se como os motivos que mais impedem a inovação.

A inovação social proporciona novas formas de agir e pensar na relação entre homem, natureza e sociedade, acarretando mudanças paradigmáticas no desenvolvimento rural sustentável e solidário (CAJAIBA-SANTANA, 2014; DELGADO et al., 2011).

No que tange a faixa etária dos informantes observou-se que mais de $50 \%$ dos entrevistados se encontra entre 41 e 60 anos, sendo que o mínimo e o máximo da idade são 18 e 83 anos. A mediana, que divide a amostra em 50\% e 50\%, é muito próxima à média respectivamente 50 e 49,47 e isso indica uma boa distribuição de valores em torno do valor '50', porem com um coeficiente de variação de $30 \%$. Essas ocorrências foram próximas as análises de Santos et al. (2013) ao caracterizarem quintais produtivos agroecológicos na comunidade Mem de Sá, Itaporanga d’Ajuda/Sergipe, onde 74\% dos informantes possuíam idade acima de 40 anos, enquadrando-se nas faixas de adultos e idosos, evidenciando assim pouca participação dos jovens no manejo dos quintais.

Nota-se que de um modo geral as propriedades são gerenciadas por pessoas mais idosas, implicando maiores dificuldades no manejo do quintal e propriedade rural. De acordo com Ferreira et al. (2012) as pessoas mais velhas possuem restrições inerentes à própria idade, como a força física e a resistência em aprender coisas novas, quando comparado aos mais jovens. Tal fato se explica à própria dificuldade de receber e processar informações de forma mais lenta. Embora a afirmação este é um fato que deve ser olhado com cautela, dado o preconceito brasileiro de que idosos são pessoas cansadas e improdutivas.

Em relação ao estado Civil dos entrevistados (Tabela 3), é possível observar que quase metade dos entrevistados são casados, um valor de 48,98\%, em seguida o estado civil mais incidente é solteiro, com 28,57\%. As outras classificações, união estável, divorciado, viúvo, outros, têm uma frequência menor, sendo respectivamente, 9,18\%, 6,12\%, 4,08\% e 3,06\%. Para este quesito foi considerada a amostra de 98 pessoas, pois uma não respondeu a essa questão.

Tabela 2: Tabela de frequências do Estado Civil dos agricultores entrevistados.

\begin{tabular}{|l|l|l|}
\hline Estado Civil & Frequência & $\%$ \\
\hline Solteiro & 28 & 28,57 \\
\hline Casado & 48 & 48,98 \\
\hline Divorciado & 6 & 6,12 \\
\hline União Estável & 9 & 9,18 \\
\hline Viúvo & 4 & 4,08 \\
\hline Outros & 3 & 3,06 \\
\hline Total & 98 & 100 \\
\hline
\end{tabular}

É importante segundo Delunardo (2010) mensurar o número de indivíduos por família com a finalidade de se esboçar um melhor perfil socioeconômico, não apenas dos informantes, mas também da 
família como um todo. $O$ número de residentes na família variou de 01 a 16 pessoas conforme pode-se visualizar na figura 1.

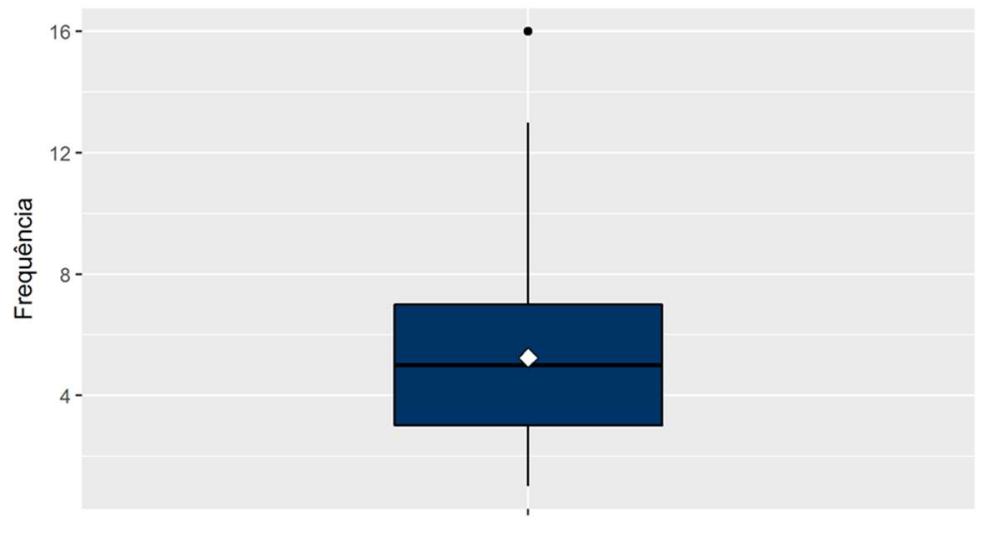

Número de residentes

Figura 1: Gráfico Boxplot referente ao número de residentes.

Com base na análise do gráfico XX o número de residentes está entre 1 e 16, que é o máximo, e foi considerado, no boxplot, como um valor discrepante. Em relação aos quartis, constata-se que $25 \%$ dos quintais possuem abaixo de 3 residentes e outros $25 \%$ acima de 7 residentes. Por fim, $61,62 \%$ dos quintais possuem entre 1 a 5 residentes. Assim, pode-se dizer que em grande parte dos quintais entrevistados, só restam na residência o casal, que em sua maioria são idosos, e em alguns casos o casal não tem filhos.

Contudo, o tamanho das famílias rurais segundo Alves et al. (2012) sofre transformações lentas e continuam sendo maiores que as domiciliares em áreas urbanas, devendo ser considerados fatores como diferenciação cultural e geográfica. Segundo Wanderley (2000) pode-se levantar a presunção de que, visto o meio rural em seu conjunto, a população que nele reside é formada, em grande maioria, pelas pessoas que se relacionam em função da referência ao patrimônio familiar. Embora seja este o perfil predominante na maioria das regiões rurais brasileiras, em diversas outras, a população rural tem hoje uma característica social distinta, prevalecendo uma população que vem deixando as cidades para instalar-se no meio rural.

Quando indagados sobre o número de filhos de cada entrevistado, observou-se que $52 \%$ dos entrevistados possui um, dois, três enquanto $10,20 \%$ não possui nenhum filho. Devido à alta concentração de amostras temos a média de filhos sendo aproximadamente 3 . Vale lembrar que $25 \%$ dos entrevistados possuem no máximo 2 filhos, $50 \%$ no máximo 3, 75\% no máximo 5 e todos os entrevistados que possuem mais de 5 filhos representam apenas $25 \%$ da amostra (Figura 2).

Um relato preocupante foi descrito no estudo de Gomes (2010) no estado do Paraná, em que 50\% dos quintais analisados existe um desinteresse das novas gerações pelos cultivos, as quais não possuem tempo para cuidar dos quintais, pois são assalariados ou, então por não ter vocação para atividades agropecuárias. Para Guillaumin et al. (2005) existe uma enorme dificuldade na sucessão dentro da agricultura familiar, com a saída de membros da família, que buscam outras oportunidades de trabalho no comercio e na indústria. A escolaridade dos agricultores entrevistados é baixa, conforme apresenta a tabela 3. 


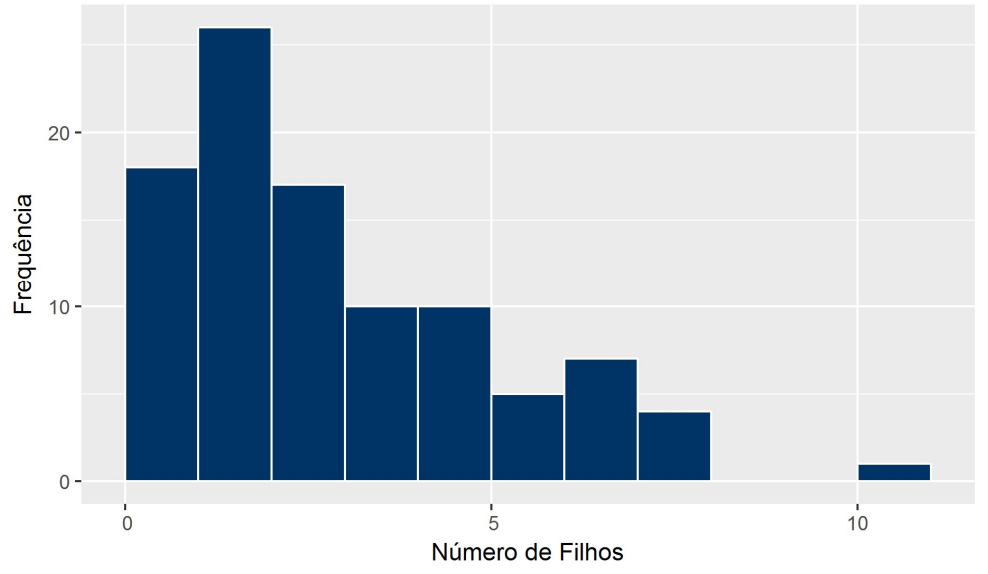

Figura 2: Gráfico de frequências do número de filhos dos agricultores entrevistados.

Tabela 3: Tabela de frequências do Nível de Escolaridade dos agricultores entrevistados.

\begin{tabular}{|l|l|l|}
\hline Nível de Escolaridade & Frequência & $\%$ \\
\hline Ensino Fundamental Incompleto & 40 & 40,4 \\
\hline Ensino Médio Completo & 24 & 24,24 \\
\hline Ensino Fundamental Completo & 11 & 11,11 \\
\hline Ensino Médio Incompleto & 10 & 10,1 \\
\hline Não Frequentou a Escola & 7 & 7,07 \\
\hline Graduação & 4 & 4,04 \\
\hline Curso Técnico Profissionalizante & 2 & 2,02 \\
\hline Pós-Graduação & 1 & 1,01 \\
\hline Total & 99 & 100 \\
\hline
\end{tabular}

A partir desses resultados conclui-se que os agricultores familiares da região de Ponte Alta - Gama possuem pouco grau de instrução. Cerca de $40 \%$ dos entrevistados não terminou o ensino médio e apenas 1 fez pós-graduação, vale notar que mais de $70 \%$ da amostra não chegou a terminar o ensino médio e também que há uma forte tendência a parar os estudos no Ensino Fundamental, já que aproximadamente $40 \%$ dos entrevistados não chegaram a termina-lo.

Analisando a tabela 3, o número de pessoas que concluiu o Ensino Médio é um pouco mais da metade dos que não concluíram o Fundamental e maior que a soma de quem não concluiu o Ensino Médio com quem concluiu o Fundamental. Essa informação é condizente com os dados levantados no Censo Agropecuário de 2006 (IBGE, 2006) e refletem a realidade da população que vive no meio rural.

O número de indivíduos que abandonou o ensino fundamental é expressivamente maior que as outras categorias. Apesar disso, quando se pensa em prática profissional, pode-se aferir que a escolaridade é um fator que auxilia e que promove a gestão da propriedade rural, porém não é uma condição primordial para o manejo das atividades agrícolas nos quintais dos agricultores familiares, pois a principal necessidade está relacionada a compreensão da natureza.

A educação no entendimento de Belchior et al. (2014) é uma das razões que elucida a permanência ou a superação da pobreza. Helfand et al. (2010) admitiram que o conhecimento colabora para a elevação da produtividade e uso adequado de tecnologias e insumos agrícolas, sendo também importante no processo de transferência de renda.

Rodrigues et al. (2017) apontaram a falta de oferta e de estrutura de ensino como fator de empobrecimento de comunidades rurais, no entanto, para Schultz et al. (2017) a escolaridade não foi um 
fator dependente para o trabalho na agricultura orgânica, pois mesmo com a baixa escolaridade os agricultores da região da Serra Gaúcha/RS superaram desafios de produção e de comercialização em um mercado inovador e em formação.

A baixa escolaridade pode delimitar o acesso à inovação tecnológica e informações, como a disponibilidade de crédito rural, produção sustentável, conservação do solo e da água, saúde pública, acesso a melhores mercados, notáveis para o progresso da pratica agroflorestal na região de Ponte Alta - Gama e demais regiões rurais do Brasil. Apesar disso, quando se pensa em prática profissional, pode-se aferir que a escolaridade é um fator que auxilia e que promove a gestão da propriedade rural, porém não é uma condição primordial para o manejo das atividades agrícolas nos quintais dos agricultores familiares, pois a principal necessidade está relacionada a compreensão da natureza. No desenvolvimento rural sustentável segundo Mendes et al. (2014) é fundamental consolidar uma categoria básica que são os agricultores familiares.

A educação para o campo torna-se uma ferramenta importante a ser introduzido em comunidades rurais, trazendo luz as questões não apenas ambientais como também políticas e sociais. Segundo Mosquen et al. (2014) o Programa Nacional de Integração da Educação Profissional Técnica de Nível Médio na Modalidade de Educação de Jovens e Adultos (PROEJA) em Escolas do Campo surgiu como possibilidade de fortalecimento e potencialização da Educação da população de áreas rurais. Através do PROEJA cria-se oportunidades para que se possa obter renda por meio dos empreendimentos locais. Destaca-se a Economia Solidária como forma de organização econômica de produção por meio da cooperação, no trabalho associado, na autogestão e na sustentabilidade (CALDART, 2008).

Segundo relatos dos Serviço Nacional de Aprendizagem Rural (SENAR, 2013) a educação profissional no Brasil deve preencher uma lacuna de formação deixada pela educação básica pública, de histórico reconhecidamente frágil em nosso país, e seus gestores precisam entender as visíveis e diferentes especificidades dos meios rurais e urbanos, para formatarem estratégias de formação adequadas aos diferentes públicos. De acordo com o Censo Demográfico 2010 (IBGE, 2010), enquanto na zona urbana a taxa de analfabetismo é de 7,3\% da população com 15 anos ou mais de idade, no campo chega a 23,2\%. De acordo com o censo, no meio rural brasileiro, vivem 6,1 milhões de adolescentes e jovens entre 14 e 24 anos (IBGE 2010). Assim, instituições de Educação pública devem planejar e realizar cursos de Aprendizagem Rural destinados aos adolescentes e jovens de 14 até 24 anos, proporcionando-lhes educação e formação para o trabalho (SENAR, 2013).

A maioria dos informantes dos quintais agroflorestais são donos das propriedades em que residem (66,66\% da amostra), enquanto outra parte vive em sítio alugado ou arrendado, juntos somam 9,09\%. Cerca de 23,24 \% dos informantes julgam ter a propriedade em processo de regularização fundiária, processo esse fundamental para serem donos do terreno (Figura 3).

A questão agrária brasileira e seus impasses referente à terra segundo Pacheco et al. (2010) estabelecem um dos desafios a serem superados nos dias atuais. É uma realidade e de segmentos sociais no sentido de constituírem uma estrutura fundiária mais justa e igualitária. Para os agricultores familiares 
entrevistados que definiram o terreno em processo de regularização, essa é uma pratica comum em todo o Brasil, que culmina no atraso social destas famílias que em sua maioria vivem em condições precárias.

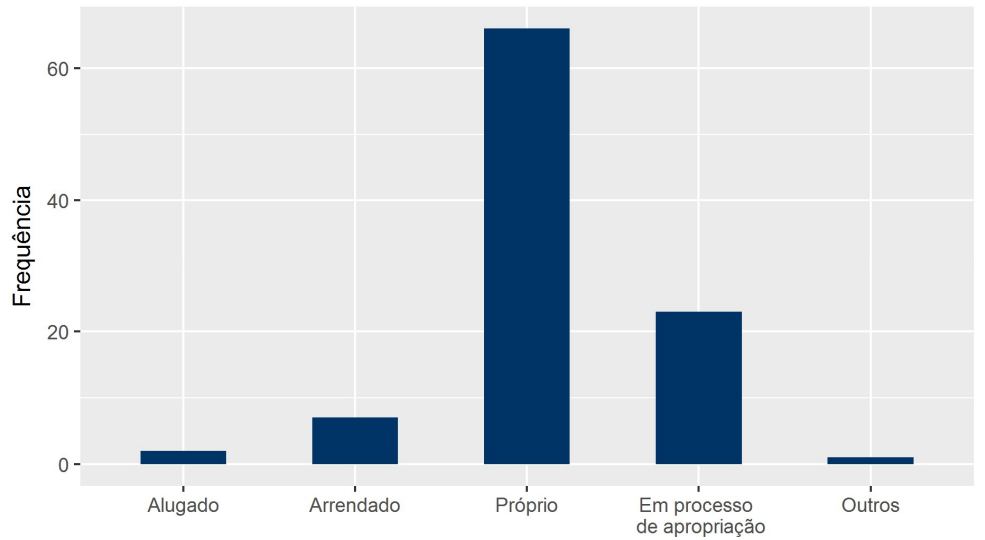

Figura 3: Gráfico de frequências do tipo de residência atribuído pelo agricultor entrevistado.

Foi solicitado para cada entrevistado numerar a importância da fonte de renda, as opções sendo: ganhos recebidos pela venda de produtos produzidos na propriedade (agrícola ou animal); ganhos de salários/diárias/contratos fora da propriedade; ganhos de aposentadoria; outros. Com base na opção com maior nota, foi feito um levantamento de qual a fonte de renda mais importante, em caso de empate foram consideradas ambas. Segue a análise apresentada na tabela 4.

Tabela 4: Tabela de frequências da fonte de renda de maior importância.

\begin{tabular}{|c|c|c|}
\hline Fonte de renda & Frequência & $\%$ \\
\hline Por fora & 50 & 51,02 \\
\hline Propriedade & 26 & 26,53 \\
\hline Propriedade e Por fora & 13 & 13,27 \\
\hline Aposentadoria & 5 & 5,10 \\
\hline Propriedade e Aposentadoria & 1 & 1,02 \\
\hline Propriedade, Por fora e Aposentadoria & 1 & 1,02 \\
\hline Outros & 2 & 2,04 \\
\hline Total & 98 & 100 \\
\hline
\end{tabular}

A fonte de renda que foi considerada mais importante para os entrevistados foi a 'Por fora da propriedade', em que 51,02\% dos indivíduos consideram a principal, sem contar os que consideram ser 'Propriedade e Por fora' e 'Propriedade, Por fora e Aposentadoria', que são, respectivamente, 13,27\% e 1,02\%, totalizando assim 65,31\% que consideram a renda 'Por fora da propriedade' como uma das principais. Em seguida, a fonte de renda considerada mais importante foi a proveniente da propriedade, em que $26,53 \%$ citou como sendo a mais importante, $13,27 \%$ afirmou ser tão importante quanto por fora, $1,02 \%$ consideram como mais importante a vinda da propriedade e da aposentadoria e 1,02\% consideram as três de igual importância, totalizando assim, 41,82\% que acreditam que a renda vinda da propriedade seja uma das de maior importância. Por fim, apenas 5,10\% colocam a renda da aposentadoria como principal, 1,02\% da propriedade e aposentadoria e 1,02\% das três igualmente, somando assim 7,14\% os que consideram aposentadoria como um dos destaques.

Para Fantineli et al. (2016) progressivamente está se tornando comum, uma unidade familiar ter outras ocupações para a geração de renda que não seja agrícola. Os agricultores familiares estão buscando 
novas formas para alcançarem um maior rendimento, e assim, melhorar a qualidade de vida. Nas descobertas de Alves et al. (2017) ao analisarem a percepção ambiental dos moradores de Uberlândia sobre a Estação Ecológica do Panga, ao descreverem as características socioeconômicas dos 300 informantes, constataram que $59 \%$ eram do sexo feminino, $65 \%$ estavam em situação de matrimónio, $28 \%$ com segundo grau incompleto e tendo uma renda média mensal individual de $\mathrm{R} \$ 724,96$ ao mês, sendo inferior ao salário mínimo da época, que estava fixado à $R \$ 788,00$.

Quando sondado os informantes sobre a relação Despesas x Ganhos (Tabela 05), constatou-se, que para esta variável, a resposta 'Lucro' foi pouco mencionada 4,04\% das vezes e que ela, somada à resposta 'Equilibrado' somam 48,48\%, sendo, ainda assim, inferior à resposta 'Prejuízo', com 51,52\% da amostra, mostrando-se absoluta nesta questão. O que significa que a grande maioria dos entrevistados possuem baixa renda e quintais não lucrativos, ou seja, suas despesas excedem seus ganhos. Os resultados mencionados anteriormente corroboram com os dados de demais autores, onde prevalece o uso dos quintais apenas para alimentação e em alguns casos complementação de renda.

Tabela 5: Tabela de frequências das despesas e ganhos mensais.

\begin{tabular}{|l|l|l|}
\hline Situação Financeira & Frequência & $\%$ \\
\hline Prejuízo & 51 & 51,52 \\
\hline Equilibrado & 41 & 44,44 \\
\hline Lucro & 4 & 4,04 \\
\hline Total & 99 & 100 \\
\hline
\end{tabular}

Segundo Pessoa et al. (2006), os quintais não perfazem fatalmente o papel de provedor de renda adicional, porém conduzem a uma economia significativa, uma vez que certos alimentos deixam de ser adquiridos no mercado local. Dessa maneira, assumem importância relevante na segurança alimentar, ampliando as possibilidades impostas pela limitação de recursos econômicos e de espaço físico (FREITAS et al., 2007).

É importante perceber que os residentes dos quintais agroflorestais são pessoas que tem uma relação longa com o campo, ali vivendo a maior parte de suas vidas. Assim, segundo Gervazio et al. (2016), acredita-se que procuram continuar com esses saberes tradicionais e culturais herdados de seus familiares, cultivando, criando animais e estando em contato com os recursos naturais.

Nessa sequência, todos esses elementos traçados do perfil agrossocial expõem como são os agricultores familiares residentes na Região de Ponte Alta - Gama, permitindo assim a clareza da realidade e dos obstáculos que esses agricultores enfrentam, visto que, o conhecimento da sua identidade segundo Silva et al. (2015) oportuniza a busca por caminhos que melhorem a qualidade de vida, promovendo a manutenção da agricultura familiar e a conservação dos recursos florestais.

A agricultura familiar se apresenta como um segmento que tem sérios obstáculos para sua reprodução social. E mesmo com as dificuldades encontradas, a agricultura familiar se caracteriza como uma organização adequada para fomentar o desenvolvimento rural (CAPORAL et al., 2007). Para Grisa et al. (2015) a discussão do Desenvolvimento Rural leva-nos a refletir sobre os elementos históricos e socioeconômicos que se processam na vida dos atores, tanto rurais como urbanos. 
Uma análise socioeconômica das famílias de agricultores segundo Pavão et al. (2006) pretende captar e encontrar respostas para que os agricultores sejam capazes de obter o seu desenvolvimento no campo. Silva et al. (2016) ressaltam que o estudo social é baseado no contexto familiar e na realidade social, tendo como finalidade subsidiar decisões e ações, possibilitando a coleta de informações a respeito da realidade sócio familiar.

\section{CONCLUÕES}

Os resultados da pesquisa indicam que o baixo grau de instrução formal dos agricultores familiares entrevistados, constituem elementos restritivos ao desenvolvimento de práticas orientadas para uma agricultura sustentável e agroecológica. Ao observar que a renda obtida a partir de investimentos na propriedade é baixa, verifica-se que os recursos provenientes da unidade de produção não são suficientes para suprir as necessidades das famílias, levando-as a envidar esforços na busca de outras rendas fora da propriedade rural. Esse fenômeno pode ser identificado com mais uma restrição da manutenção do homem do campo e do desenvolvimento rural sustentável, demandando da esfera pública a melhoria de políticas públicas que permitam a valorização e incentivo a práticas agrícolas que visão a preservação do meio ambiente.

A baixa renda pode influenciar ainda a falta de adoção de práticas de manejo sustentável ou alternativas, uma vez que estas são mais complexas, aumentando o consumo de agrotóxicos que acabam por aumentar a produtividades das culturas agrícolas. Atenta-se para os resultados referentes à faixa etária e a participação da mulher nas propriedades, onde $47,2 \%$ dos responsáveis pela propriedade possuem mais de 51 anos. A elevada idade dos proprietários deve ser olhada com cautela, pois requer iniciativas diferenciadas de aprendizagem e orientações. Tal fato implica na avaliação dos modelos de treinamento e capacitação oferecidos a estas pessoas. Modelos convencionais podem não ser adequados para a demanda existente. Iniciativas como o Programa de Educação de Jovens e Adultos - PROEJA, podem responder às especificidades, mas não são suficientes para os conhecimentos técnicos e operacionais da agricultura sustentável.

Ações do Serviço Nacional de Aprendizagem Rural - SENAR e demais instituições públicas de ensino como Universidades e Institutos Federais, devem levar em conta essa característica específica da população, ignorando o preconceito da dificuldade de aprendizagem dos mais idosos. Ainda neste cenário, propõe-se o estimulo do jovem agricultor, com ações de educação específica para o homem do campo, como nos modelos de escolas rurais, escola de alternância de qualidade, que visa geração de renda e fixação do jovem no campo.

\section{REFERÊNCIAS}

AJEESH, R.; KUMAR, V.; KUNHAMU, T. K.. Floristic Analysis of Peri-Urban Homegardens of Southern Kerala, India. Indian Journal of Ecology, v.42, n.2, p.300-305, 2015.

ALVES, W. F.; ARAÚJO, A. A.; SILVA, C. R.. Percepção ambiental dos moradores de Uberlândia sobre a estação ecológica do Panga - uma visão sob a ótica da economia do meio ambiente. Revista Ibero-Americana de Ciências
Ambientais, v.8, n.4, p.309-326 2017.

DOI: $\underline{\text { https://doi.org/10.6008/SPC2179-6858.2017.004.0025 }}$

ALVES, K. S.; MOTA, D. M.. Organização do trabalho familiar do espaço rural paraense: Novos arranjos na organização do trabalho e na gestão das unidades de produção. R. Inter. Interdisc. Interthesis, Florianópolis, v.9, n.2, p.191-215, 2012. 
BAILEY, K. D.. Methods of social research. New York: Free Press, 1982.

BELCHIOR, E. B.; SOUZA, J. D. F.; ALMEIDA, H. C. G.; MORAIS, O. R.; SHIOTSUKI, L.. A importância do perfil socioeconômico de criadores de ovinos de corte na elaboração de políticas públicas. In: CONGRESSO SOBER: SOCIEDADE BRASILEIRA DE ECONOMIA, ADMINISTRAÇÃO E SOCIOLOGIA RURAL, 52. Anais. Goiânia, 2014.

BRITO, M. A.; COELHO, M. F. B.. Os quintais agroflorestais em regiões tropicais-unidades autossustentáveis. Revista Agricultura Tropical, Cuiabá, v.1, n.4, p.7-38, 2000.

CAJAIBA-SANTANA, G.. Social innovation: moving the field forward. A conceptual framework. Tecnological Forecasting \& Social Change, v.82, p.42-51, 2014.

CALDART, R. S.. Sobre Educação do Campo. In: SANTOS, C. A.. Por Uma Educação do Campo: Campo - Políticas Públicas - Educação. Brasília: INCRA, MDA, NEAD Especial, 2008.

CAPORAL, F. R.; COSTABEBER, J. A.. Agroecologia: alguns conceitos e princípios. 2 ed. Brasília: MDA, SAF, DATER-IICA, 2007.

CASTRO, C. N.; PEREIRA, C. N.. Agricultura familiar, assistência técnica e extensão rural e a política nacional de ATER. Brasília: Rio de Janeiro: Ipea, 2017.

DELGADO, N. G.; LEITE, S. P.. Políticas de desenvolvimento territorial no meio rural brasileiro: novas institucionalidades e protagonismo dos atores. Revista Dados, v.54, n.2, p.431473, 2011.

DELUNARDO, T. A.. A agrobiodiversidade em quintais urbanos de Rio Branco, Acre. Dissertação (Mestrado em Agronomia) - Universidade Federal do Acre. 2010.

EMATER. Empresa de Assistência Técnica e Extensão Rural do Distrito Federal. Relatório de atividades 2017, N. 013347/2017: Portal da transparência. Ouvidoria, 2017.

FANTINELI, D. G.; FERREIRA, A. G.; GODOY, C. M. T.; BELING, H. M.. A agricultura familiar e suas estratégias de sobrevivência. In: SEMINÁRIO NACIONAL DE DESENVOLVIMENTO REGIONAL, 1. Anais. Taquara, 2016

FAO. Food and Agriculture Organization of the United Nations. Agroforestry for landscape: restoration Exploring the potential of agroforestry to enhance the sustainability and resilience of degraded landscapes. Rome, 2017.

FRANCO, F. S.; OLIVEIRA, J. E.; ALVARES, S. M. R.. Construção participativa do conhecimento agroflorestal e monitoramento de indicadores de sustentabilidade em assentamentos rurais na região de Iperó, SP. In. CANUTO, J. Sistemas agroflorestais: experiências e reflexões. Brasília: Embrapa, 2017. 216p.

FREITAS, M. C. S.; PENA, P. G. L.. Segurança alimentar e nutricional: a produção do conhecimento com ênfase nos aspectos da cultura. Revista Nutrição, v.20, n.1, p.69-81 2007.

GERVAZIO, W.; BERGAMASCO, S. M. P. P.; MAZALLA NETO, W.; YAMASHITA, O. M.; ROBOREDO, D.. Sustentabilidade: o
Caminho é a Agroecologia. Cadernos de Agroecologia, v.11, p.1-12, 2016

GIL, A. C.. Métodos e técnicas de pesquisa social. 5 ed. São Paulo: Atlas, 1999

GOMES, G. S.. Quintais agroflorestais no município de Irati, Paraná, Brasil: Agrobiodiversidade e socioeconomia. Tese (Doutorado em Ciências Agrárias) - Universidade Federal do Paraná, 2010.

GRISA, C.; SCHNEIDER, S.. Políticas públicas de desenvolvimento rural no Brasil. Porto Alegre: UFRGS, 2015 .

GUILLAUMIN, A.; KLING-EVEILLARD, F.; MOREAU, J. C.. Résulats d'enquêtes en Aquitaine. Quand les éleveurs laitiers parlent de leurs conditions de travail. Travaux et Innovations, v.115, n.1, p.30-35, 2005

HELFAND, S.; PEREIRA, V.. Determinantes da pobreza rural e implicações para as políticas públicas no Brasil. In: BUAINAIN, A. M.; DEDECCA, C.. A nova cara da pobreza rural: desafios para as políticas públicas. Série Desenvolvimento Rural Sustentável. Brasília: IICA, 2010.

IBGE. Instituto Brasileiro de Geografia e Estatística. Censo Agropecuário 2006: Agricultura Familiar primeiros resultados. Censo Agropecuário. Rio de Janeiro: Ministério do Desenvolvimento Agrário, 2006.

IBGE. Instituto Brasileiro de Geografia e Estatística. Censo Demográfico 2010: Características gerais da população, religião e pessoas com deficiência. Censo Demográfico. Rio de Janeiro: Ministério do Planejamento, Orçamento e Gestão, 2010.

INCRA. Instituto Nacional de Colonização e Reforma Agrária. Sistema Nacional de Cadastro rural: Tabela com módulos fiscais dos municípios. Ministério do Desenvolvimento Agrário, 2013.

IPARDES. Diagnóstico sócio econômico do território CentroSul do Paraná. 2007.

KOTTER, P. J.; SCHLESINGER, A. L.. Escolhendo estratégias para a mudança. In: KOTTER, P. J.. Afinal, o que fazem os líderes: a nova face do poder e da estratégia. Rio de Janeiro: Campus, 2000.

LOPES, K. C. A.; BORGES, J. R. P. B.; LOPES, P. R.. Percepção ambiental de agricultores familiares assentados como fator preponderante para o desenvolvimento rural sustentável. In: CONGRESSO BRASILEIRO DE AGROECOLOGIA, 7. Anais. Fortaleza, 2011.

MACEDO, M. C. M.. Integração lavoura e pecuária: o estado da arte e inovações tecnológicas. Revista Brasileira de Zootecnia, v.38, p.133-146, 2009.

MARAVIESKI, E. L.; REIS, D.. Avaliação de resistência à mudança em processos de inovação: a construção de um instrumento de pesquisa. In: ENCONTRO NACIONAL DE ENGENHARIA DE PRODUÇÃO, 28. Anais. Rio de Janeiro: ABEPRO, 2008 
MARCONI, M. DE A.; LAKATOS, E. M.. Metodologia científica. 4 ed. São Paulo: Atlas, 2004

MATTAR, F. N.. Pesquisa de marketing: metodologia, planejamento. 5. ed. São Paulo: Atlas, v.1, 1999.

MENDES, M. F.; NEVES, S. M. A. S.; SILVA, J. S. V; NEVES, R. J.; SILVA, T. P.. Perfil dos agricultores familiares extrativistas da região Sudoeste Matogrossense, pertencente à bacia do Alto Paraguai - Brasil. Revista Bol. Geografia, v.32, n.3, p.94-109, 2014.

MOSQUEN, M. H. R.; BEAL, Z.; AGOSTINI, A. D.. Educação do Campo: Educação que promove a dignidade do povo campesino. In: D'AGOSTINI, A.. Experiências e reflexões sobre escolas/classes multisseriadas. Florianópolis: Insular Livros, 2014.

PACHECO, R. A. S.; PACHECO, C. R.. Questão agrária e regularização fundiária: a ação dos estados e o conflito de interesses entre trabalhadores rurais sem terra e povos indígenas. Revista Planejamento e Políticas públicas, n.34, p.259-268, 2010

PAVÃO, A. P. A. R.; GRACIANO, M. I. G.; BLATTNER, S. H. B.. Os indicadores do estudo sócio econômico na construção do relatório social no Hospital de Reabilitação de Anomalias Craniofaciais. Serviço Social \& Saúde, Campinas, v.5, n.5, p.183-216, 2006

PEREIRA, C. N.; MANESCHY, R. Q.; OLIVEIRA, P. D.; OLIVEIRA, I. K. S.. Caracterização de quintais agroflorestais no projeto de assentamento Belo Horizonte I, São Domingos do Araguaia, Pará. Agroecossistemas, v.2, n.1, p.73-81, 2010.

PEREIRA, L. G.; VIEIRA, F. J.; ALENCAR, N. L.; CARVALHO, F. A.; BARROS, R. F. M.. Diversidade florística em quintais do Nordeste brasileiro: um estudo etnobotânico em comunidades rurais em Monsenhor Gil/PI. Espacios, v.37, n.20, p.11, 2016

PEREIRA, P. V. M.; FIGUEIREDO NETO, L. F.. Conservação de espécies florestais: um estudo em quintais agroflorestais no município de Cáceres - MT. Revista Eletrônica em Gestão, Educação e Tecnologia Ambiental, Santa Maria, v.19, n.3, p.783-793, 2015.

PESSOA, C. C.; SOUZA, M.; SCHUCH, I.. Agricultura urbana e Segurança Alimentar: estudo no município de Santa Maria, RS. Segurança Alimentar e Nutricional, v.13, n.1, p.23-37, 2006.

R CORE TEAM. R: A language and environment for statistical computing. R Foundation for Statistical Computing, Vienna, 2016.

RODRIGUES, P. L.; GUIMARÃES, J. B.; MARTINS, C. M.; SANTOS, M. A. S.; REBELLO, F. K. Dinâmica socioeconômica e organizacional em comunidade remanescente do quilombo Rio Gurupá, Marajó, Pará. Revista Verde, v. 12, n. a, p. 105116, 2017

RODRIGUEZ-OCAÑA, A.. Propuesta metodológica para el análisis de la toma de decisiones de los agricultores: aplicación al caso del regardío extensivo cordobés. Tese (Doctorado en Economia Agroalimentares - Universidad de Córdoba, Madrid, 1996.
ROSA, L. S.; VIEIRA, T. A.; SANTOS, A. P. A.; MENESES, A. A. S.; RODRIGUES, A. F.; PEROTE, J. R. S.; LOPEZ, C. V. C.. Limites e oportunidades para a adoção de sistemas agroflorestais pelos agricultores familiares da microrregião Bragantina, $\mathrm{Pa}$. In: PORRO, R... Alternativa agroflorestal na Amazônia em transformação. Brasília: Embrapa/ICRAF, 2009. p.645-670.

SALES, C. M. V.. Mulheres rurais: tecendo novas relações e reconhecendo direitos. Estudos Feministas, v.15, n.2, 2007. DOI: http://dx.doi.org/10.1590/S0104-026X2007000200010

SANTOS, A. S.; OLIVEIRA, L. C.; CURADO, F. F.; AMORIM, L. O.. Caracterização e desenvolvimento de quintais produtivos agroecológicos na comunidade Mem de Sá, Itaporanga d'Ajuda - Sergipe. Revista Brasileira de Agroecologia, v.8, n.2, p.100-111, 2013.

SANTOS, S. D.; GUARIM NETO, G.. Etnoecologia de quintais: estrutura e diversidade de usos de recursos vegetais em Alta Floresta. In: GUARIM NETO, G.; CARNIELLO, M. A.. Quintais mato-grossenses: espaços de conservação e reprodução de saberes. Cáceres: UNEMT, 2008. p.201

SCHROTH, G.; FONSECA, G. A. B.; HARVEY, C. A.; GASCON, C.; VASCONCELOS, H. L.; IZAC, A. M. N.. Agroforestry and biodiversity conservation in tropical landscapes. Washington: Island Press, 2004.

SCHULTZ, G.; SOUZA, M.; JANDREY, W. F.. Motivações e acesso aos canais de comercialização pelos agricultores familiares que atuam com produção orgânica na Região da Serra Gaúcha. Redes - Santa Cruz do Sul, Universidade de Santa Cruz do Sul, v.22, n.3, 2017.

SENAR. Serviço Nacional de Aprendizagem Rural. Aprendizagem Rural: documento norteador / Serviço Nacional de Aprendizagem Rural. 4 ed. Brasília: SENAR, 2013.

SILIPRANDI, E.. Agroecologia, agricultura familiar e mulheres rurais. Revista Brasileira de Agroecologia, v.2, n.1, 2007.

SILVA, D. V.; LACERDA, A. V.; GOMES, A. C.; SILVA, K. K.; OLIVEIRA, L. N. R.. A importância das mulheres para os quintais agroflorestais da comunidade rural Cabeça Branca no município de Sumé, Paraíba, Brasil. Cadernos de Agroecologia, v.10, n.3, 2015.

SILVA, W. C.; FERREIRA, A. A. S.; MARTINS, A. S.; COSTA, M. B. T.; ARRUDA, A. S.. Utilização de plantas medicinais pela comunidade periférica do município de Ipameri -Goiás. In: CONGRESSO DE ENSINO, PESQUISA E EXTENSÃO DA UEGINOVAÇÃO: INCLUSÃO SOCIAL E DIREITOS, 3. Anais. CEPE. 2016.

TÉO, S. J.; SCHNEIDER, C. R.; FIORENTIN, L. D.; COSTA, R. H. Análise fitossociológica de um fragmento de floresta ombrófila mista, em lebon Régis - SC. IN: Congresso Florestal Parananese, 4. Anais. Curitiba, 2012.

TRIOLA, M. F.. Introdução à Estatística. Rio de Janeiro, LTC, 2008.

VASQUEZ, S. P. F.; MENDONCA, M. S.; NODA, S. N.. Etnobotânica de plantas medicinais em comunidades 
ribeirinhas do Município de Manacapuru, Amazonas, Brasil. Acta Amazonica, v.44, n.4, 2014.

VIEIRA, T. A.; ROSA, L. S.; VASCONCELOS, P. C. S.; SANTOS, M. M.; MODESTO, R. S.. Agroforestry systems in áreas of smallholder agriculture in Igarapé-Açu, Pará: floristic characterization, implantation and management. Acta Amazonica, v.37, n.4, p.549-558, 2007.

WANDERLEY, M. N. B.. Raízes históricas do campesinato brasileiro. In: WANDERLEY, M. N. B.. O mundo rural como um espaço de vida: reflexões sobre a propriedade da terra, agricultura familiar e ruralidade. UFRGS,2009. p.155-183.

A CBPC - Companhia Brasileira de Produção Científica (CNPJ: 11.221.422/0001-03) detém os direitos materiais desta publicação. Os direitos referem-se à publicação do trabalho em qualquer parte do mundo, incluindo os direitos às renovações, expansões e disseminações da contribuição, bem como outros direitos subsidiários. Todos os trabalhos publicados eletronicamente poderão posteriormente ser publicados em coletâneas impressas sob coordenação da Sustenere Publishing, da Companhia Brasileira de Produção Científica e seus parceiros autorizados. Os (as) autores (as) preservam os direitos autorais, mas não têm permissão para a publicação da contribuição em outro meio, impresso ou digital, em português ou em tradução. 